Review Article

\title{
Participation of WNT and $\beta$-Catenin in Physiological and Pathological Endometrial Changes: Association with Angiogenesis
}

\author{
Jolanta Kiewisz, ${ }^{1}$ Tomasz Wasniewski, ${ }^{2}$ and Zbigniew Kmiec ${ }^{1}$ \\ ${ }^{1}$ Department of Histology and Embryology, Faculty of Medical Sciences, University of Warmia and Mazury, \\ Warszawska 30, 10-082 Olsztyn, Poland \\ ${ }^{2}$ Department of Obstetrics and Gynecology, Faculty of Medical Sciences, University of Warmia and Mazury, \\ Zotnierska 18, 10-561 Olsztyn, Poland
}

Correspondence should be addressed to Zbigniew Kmiec; zkmiec@gumed.edu.pl

Received 21 November 2014; Accepted 15 January 2015

Academic Editor: Shi-Wen Jiang

Copyright $($ ) Jolanta Kiewisz et al. This is an open access article distributed under the Creative Commons Attribution License, which permits unrestricted use, distribution, and reproduction in any medium, provided the original work is properly cited.

WNT proteins are involved in embryonic development, sex determination, stem cell recruitment, angiogenesis, and cancer. They take part in morphological changes in the endometrium during development, regulate processes of endometrial proliferation and differentiation. This review presents current knowledge about implication of WNT proteins and $\beta$-catenin in physiological endometrial functions as well as their involvement in uterine carcinogenesis. Influence of WNT proteins on the formation of blood vessel, taking place both under healthy and pathological conditions, is also considered. Participation of WNT proteins, $\beta$-catenin, and inhibitors and inducers of WNT signaling in the process of endometrial angiogenesis is largely unknown. Thus, confirmation of their local and systemic participation in the process of endometrial angiogenesis may in the long term help to establish new diagnostic and therapeutic approaches in conditions associated with the pathology of the female reproductive system.

\section{Introduction}

WNT are proteins involved in physiological and pathological processes such as embryonic development, sex determination, malignant transformation, endothelial cell differentiation, and angiogenesis [1, 2]. Angiogenesis is required for formation and remodeling of the endometrial vascular system in the course of menstrual cycle. Impaired process of differentiation of endometrial epithelium may lead to cancer, usually accompanied by pathological angiogenesis.

In this review, we present data about implication of WNT proteins and $\beta$-catenin in physiological endometrial functions as well as their involvement in uterine carcinogenesis. We also present current knowledge about influence of WNT proteins on the formation of blood vessel, both under healthy and pathological conditions. The proposed hypothesis about participation of WNT proteins in the regulation of the formation of microvessels might provide a conceptual framework for the design of future experiments.

\section{General Characteristics of WNT Genes and Proteins}

Wingless gene is responsible for segmentation during embryogenesis and legs formation during transformation of Drosophila melanogaster. Homologous gene int-1, detected in mammals, becomes activated upon cell integration of the MMTV virus (mouse mammary tumor virus), which causes mammary tumors in mice. Comparison of the amino acid sequences of the proteins encoded by these two genes showed their high homology, while combination of the abbreviations of gene names gives the name for the whole gene family, $W N T(W N T=W g+I N T)$. To date, the largest number (19) of WNT genes was found in mice and humans. Their existence was also confirmed in the nematode Caenorhabditis elegans, zebrafish (Danio rerio), amphibians of the Xenopus genus, and chicken (Gallus gallus domesticus). Based on their capability to induce the malignant transformation in cell lines derived from murine mammary gland epithelial cells 
(C57MG), WNT genes were divided into two groups. The first group includes genes encoding cysteine-rich, secretory glycoproteins with oncogenic characteristics: WNT1, WNT3, WNT3A, WNT7, WNT8, and WNT8B, while the other encodes proteins lacking the properties to induce malignant transformation: WNT2, WNT4, WNT5A, WNT5B, WNT6, WNT7B, and WNT11 [2]. Hydrophobic nature and activity of these proteins were associated with binding of cysteine residues with palmitic acid.

WNT proteins activate the canonical (genes involved in the malignant transformation) and noncanonical (genes not involved in the malignant transformation) cell signaling pathways. Canonical signaling pathway known also as WNT/ $\beta$-catenin signaling pathway is activated by WNT proteins joined with the complex of Frizzled (FZD)/lowdensity-lipoprotein receptor-related protein (LRP) on the cell surface. Activated cytoplasmic protein called Dishevelled (DSH) inhibits the activity of a protein APC/GSK3 $\beta$ complex (Axin/Adenomatous Polyposis Coli/Glycogen Synthase Kinase $3 \beta$ ) responsible for the degradation of $\beta$-catenin. After stimulation with WNT, cytoplasmic $\beta$-catenin is translocated to the nucleus, where it activates transcription factors: T cell factor (TCF) and lymphoid enhancer factor (LEF). These transcription factors change the expression level of target genes encoding proteins implicated in cell proliferation and survival (cyclin D1, c-Myc), cellular migration (CD44), cell adhesion (CDH1), digestion of extracellular matrix (MMP7), and many others [3]. Because $\beta$-catenin binds to $\alpha$-catenin and cytoplasmic domain of E-cadherin, one of the methods of inhibiting cell signal induced by WNT is to increase the level of E-cadherin. In mammals, the activation of the $\mathrm{WNT} / \beta$ catenin pathway leads to the enhanced recruitment of stem cells and amplification of their pluripotency.

The other group of WNT which act through $\beta$-cateninindependent pathway can activate FZD receptor family. The initiation of signal cascades results in the release of calcium ions, activation of protein kinase $\mathrm{C}$ (PKC) and calciumcalmodulin dependent protein kinase II (CAMKII). It has been established that the $\mathrm{WNT} / \mathrm{Ca}^{2+}$ signal transduction pathway antagonizes the action of $\mathrm{WNT} / \beta$-catenin signaling [4] and may be associated with cell proliferation and migration [5]. In the second type of signaling pathway, the planar cell polarity pathway and FZD receptors through DSH protein activate small $\mathrm{G}$ proteins, Rac and Rho kinases, and cJun N-terminal kinase (JNK). This leads to the restructuring of the cytoskeleton proteins, migration of the cell, and the acquisition of cell polarity [2].

WNT-mediated signaling pathways can be modulated through secreted Frizzled-related proteins (sFRP) and Dickkopf (DKK) proteins. sFRP proteins bind directly to WNT proteins, while DKK proteins block LRP5/6 coreceptors. In both cases, WNT ability for signal transduction is blocked [2].

\section{WNT Genes and Proteins in the Endometrial Physiology}

3.1. WNT Proteins in the Female Reproductive Tract Development. Developmental changes of the endometrium are mainly associated with the expression of WNT4, WNT5A, and $W N T 7 A$ genes as demonstrated in mouse [6-8] and pig $[9,10]$. However, WNT4, WNT5A, and WNT7A genes expression was presented also in developed uterus in humans $[11,12]$, sheep [13], horse [14], and pig [9, 10, 15, 16].

Wnt4 gene is expressed in the primordial gonads of mouse embryos [17] and Wnt4 protein influences the process of gametogenesis [18]. During mouse embryonic development, Wnt4 gene is expressed in stromal cells of the forming endometrium [19]. In mice lacking Wnt4 gene, sex reversion, partial atrophy of the Müllerian ducts, masculinization, and morphological and functional changes of the gonads were described [18]. Moreover, mutation of Wnt4 gene in mouse causes ectopic expression of Leydig cells markers (e.g., 17-alpha-hydroxylase and 17-beta-hydroxysteroid dehydrogenase) [18]. Increased amounts of testosterone were also secreted [18].

The key role of the WNT5A gene has been documented by finding that $W n t 5 a$ knockout mice have no reproductive organs and live no longer than 24 hours [20]. Constitutively expressed $W n t 5 a$ gene was observed in mice gonadal ridges [21]. Wnt5a protein is present in the mouse endometrial stromal cells and its amount decreased in the area of myometrium formation what was established with the use of ribonuclease protection analysis and RNA in situ hybridization [20, 22, 23].

Female mice lacking Wnt7a genes expression have deformed wall of the uterus and undeveloped ovaries [6]. Moreover, it was shown that the expression of the Wnt7a may have impact on the transformation of Müllerian ducts [6].

3.2. Role of WNT Proteins in Endometrial Physiology. In physiological condition (Figure 1), WNT4 gene expression is higher in endometrial stroma in comparison to its expression in epithelial cells [12]. Injection of estradiol $\left(\mathrm{E}_{2}\right)$ into ovariectomized mice upregulated, while administration of progesterone $\left(\mathrm{P}_{4}\right)$ had no effect on, Wht4 gene expression in stromal cells of endometrium [24]. Similar pattern of expression as those of Wnt 4 was presented by Wnt5a during the luteal phase of the estrous cycle in mice [23] but expression of Wnt5a was observed only in stromal cells just before and soon after estrus occurrence [23]. However, other authors could not confirm these findings [24]. Treatment of cyclic ewes with $\mathrm{P}_{4}$ and antagonist of $\mathrm{P}_{4}$ receptor at the same time (RU 486) increased endometrial WNT5A mRNA level at day 12 of pregnancy [25].

Fan and coworkers [26] showed that WNT7A mRNA levels in the female endometrial tissue were higher in the proliferative phase in comparison to secretory phase of the menstrual cycle. However, other authors did not find correlation of the WNT7A gene expression with phases of the menstrual cycle with the use of real-time PCR, digoxigeninlabeled cRNA probes, and in situ hybridization technique $[11,27,28]$. Presumably, WNT7A expression is stimulated by estradiol [29] which coordinates WNT7A-mediated process of postmenstrual reepithelialization and regeneration of the endometrium [26]. The influence of estradiol on WNT7A gene expression was presented in in vitro culture of luminal epithelial cells of human endometrium [30] or neonatal piglets [10]. Presence of WNT7A was marked in regenerating newly formed surface epithelium and upper endometrial 


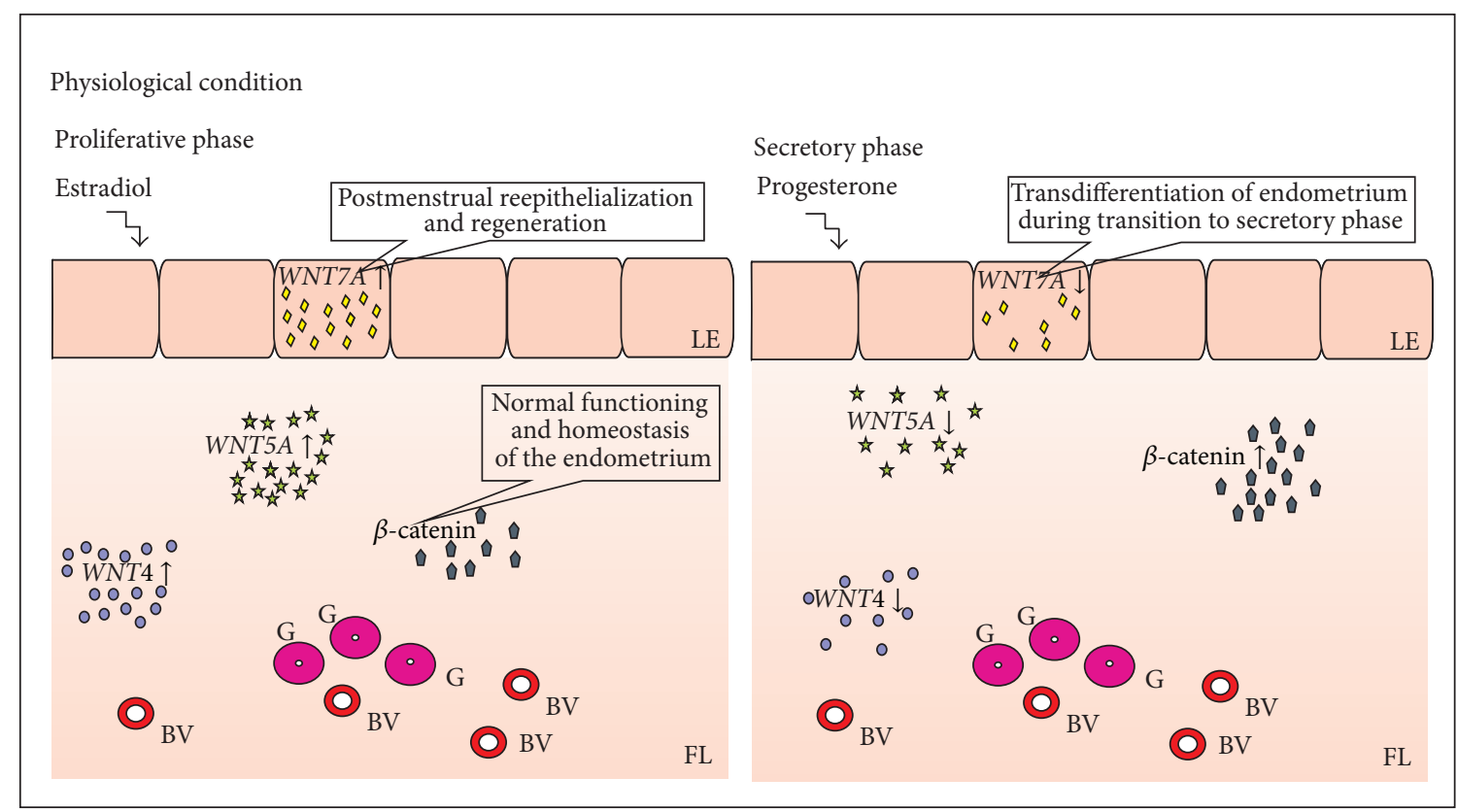

FIGURE 1: Endometrial expression of WNT genes. LE: luminal epithelium; FL: functional layer; BV: blood vessel; G: glands; $\downarrow$ : decreased gene expression; $\uparrow:$ increased gene expression.

glands [11, 26-28] but not in the lower glands and stroma of human endometrium [26, 28]. These observations support the view that luminal epithelium secretes factors that are important for glandular function and stromal transformation [11]. Moreover, progesterone-mediated downregulation of WNT7A gene expression may be essential for the transdifferentiation of endometrium during its transition to the secretory phase [26]. In mice, Wnt7a gene expression was completely suppressed in the surface epithelium and was undetectable in glandular epithelium and endometrial stroma after seven days of progesterone treatment [26].

$\beta$-catenin, the mediator of Wnt/ $\beta$-catenin signaling, was first isolated as an intracellular protein constituting the binding domain of E-cadherin with cell's cytoskeleton [31]. The available data suggest that $\beta$-catenin is essential for normal functioning of the uterus and seems to be responsible for establishing of the endometrial homeostasis [32]. In human endometrial tissue, the immunoreactivity of $\beta$-catenin was observed in intercellular borders of luminal and glandular epithelial cells as well as in stroma and endothelial cells [33]. Examples of $\beta$-catenin positive staining of physiological endometrium are presented in Figure 2.

Fujimoto and coworkers [34] revealed upregulation of $\beta$ catenin (CTNNB1) mRNA level during secretory phase in human endometrium. It correlated with steroid hormone profile because progesterone but not estradiol increased CTNNB1 mRNA level in human endometrial stromal cells cultured in vitro [35]. During proliferative phase of the menstrual cycle, the amount of nuclear $\beta$-catenin increased. $\beta$-catenin was allocated from the nucleus to the cytoplasm and cell membrane during the secretory phase [36]. However, Tulac and coworkers [11] showed no statistically significant difference in CTNNB1 gene expression in human endometrium between proliferative and secretory phases.
Moreover, usage of $\mathrm{LiCl}$, potential inhibitor of $\mathrm{WNT} / \beta$ catenin signaling, induced estradiol-mediated proliferation and hyperplasia of endometrial cells in mice [37] and humans [38]. Activation of WNT/ $\beta$-catenin signaling pathway increased endothelin 1 mRNA level which is target gene of $\beta$-catenin action as well as participant of endothelial cells differentiation [39]. Thus, it may be concluded that $\mathrm{Wnt} / \beta$-catenin signaling regulates processes of endometrial proliferation and differentiation. Specific pattern of WNT genes expression and pattern of hormonal regulations are summarized in Table 1.

\section{WNT Protein and Gene Expression in Endometrial Cancer}

4.1. General Characteristics of Endometrial Cancer. Endometrial cell carcinomas (ECCs) are the most common malignancy of the female genital tract in the Western world and the fourth most common one after breast, lung, and colorectal cancer in women. A constant increase of endometrial cancer has been observed in the recent years [40]. ECCs occur mainly in postmenopausal women at the age of 55-65. Factors increasing the probability of the endometrial carcinoma occurrence include long-term estrogen therapy, polycystic ovarian syndrome, a history of nulliparity or infertility, irregular menstrual cycles, obesity, diabetes mellitus, and hypertension [41]. The curability of EECs is as high as fiveyear survival rate for the G1 and 1st stage is $90 \%$. However, 5year survival rapidly decreases to $30-50 \%$ for the 2 nd and to $20 \%$ for the 3 rd stage [41]. Women with ECCs experience dysfunctional endometrial bleeding which makes tumor detection seemingly an easy task. However, major diagnostic and prognostic problems often arise by histopathological assessment (WHO classification) since seven types of endometrial 


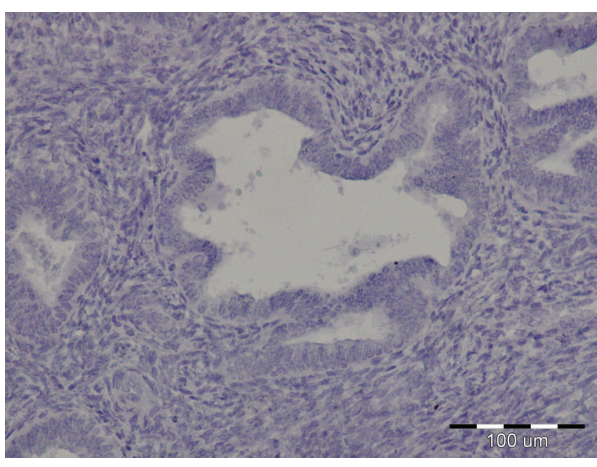

(a)

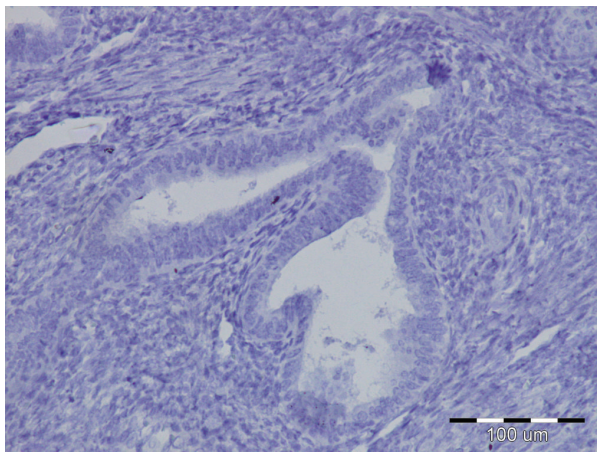

(c)

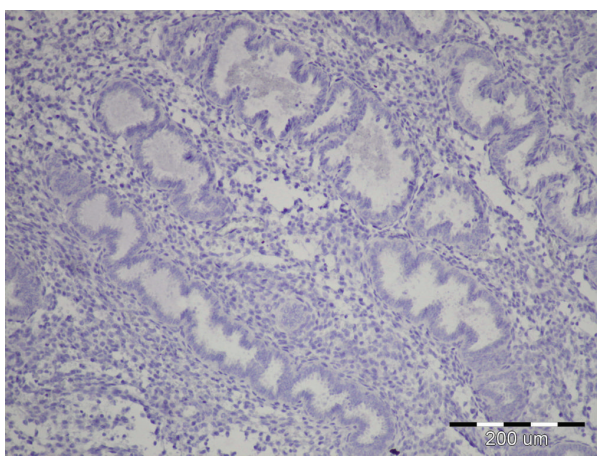

(e)

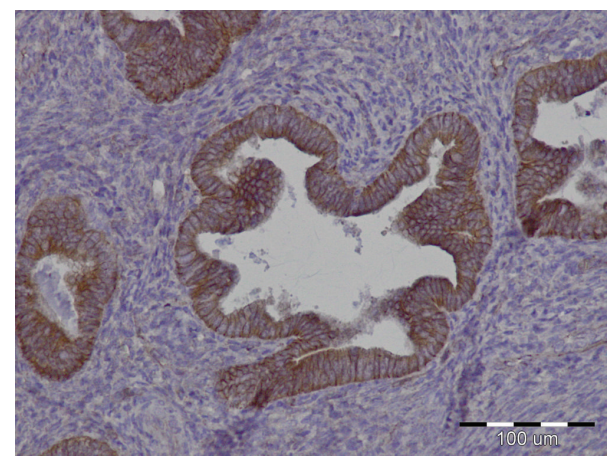

(b)

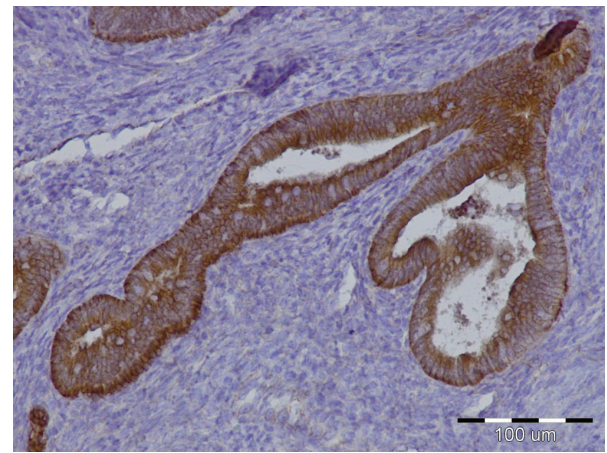

(d)

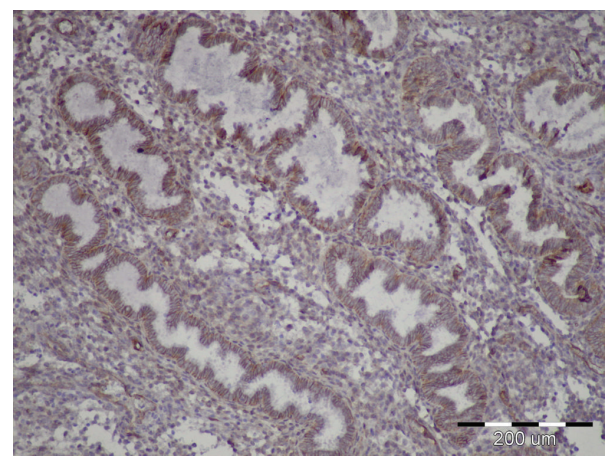

(f)

FIGURE 2: Examples of immunohistochemical staining confirming presence of $\beta$-catenin in physiological endometrium. Positive staining (BD Transduction Laboratories Cat. number 610153) of endometrial glands, magnification $\times 20$ (b, d) and $\times 10$ (f). Negative controls magnification $\times 20(\mathrm{a}, \mathrm{c})$ and $\times 10(\mathrm{e})$.

carcinoma can be distinguished. The most common subtype of ECC is an endometrial endometrioid adenocarcinoma (EEAC), classified as type I or estrogen-dependent cancer [42]. Approximately $80 \%$ of newly diagnosed endometrial carcinomas in the Western world are of the endometrioid (EEAC) type [43]. Any factor that increases exposure to unopposed estrogen (estrogen-replacement therapy, obesity, anovulatory cycles, and estrogen-secreting tumors) increases the risk of these tumors, whereas factors that decrease exposure to $\mathrm{E}_{2}$ or increase $\mathrm{P}_{4}$ levels (oral contraceptives, smoking) tend to be protective [44]. Type I endometrial cancer consists of low-grade endometrioid histology, starts with the background of endometrial hyperplasia, and may have better prognosis [41]. Endometrial serous adenocarcinoma (ESC) and clear cell endometrial carcinoma (ccEC) are aggressive neoplasia carrying a poor prognosis [45]. ESC or ccEC is estrogen-independent and is classified as type II [42]. The average age of patients with nonendometrioid cancer is 67 years, and at least half of them had cancer already spread beyond the corpus of the uterus at the time of diagnosis. The 5 -year survival is approximately $62 \%$ for clear cell carcinomas and 53\% for papillary serous cancers [44]. Although the ECCs are highly curable, there are particular morphological variations and histopathological features which do not allow for their clear identification [42]. Each subtype has specific genetic alterations showing microsatellite instability and mutations in PTEN, PIK3CA, K-ras, and CTNNBI ( $\beta$-catenin) genes summarized in Table 2 . However, their specificity as a biomarker has been widely discussed [42]. 
TABLE 1: Function and hormonal regulation of WNT and $\beta$-catenin (CTNNB1 gene) in the endometrium.

\begin{tabular}{|c|c|c|c|}
\hline & Gene & Description & References \\
\hline \multirow{8}{*}{ WNT4 } & \multirow{4}{*}{ Function } & Formation of the primordial gonads & [18] \\
\hline & & Gametogenesis & [17] \\
\hline & & Uterine wall morphogenesis & [19] \\
\hline & & Decidua formation & {$[24,60,88]$} \\
\hline & \multirow{4}{*}{ Hormonal regulation } & $\mathrm{E}_{2} \uparrow$ & {$[13]$} \\
\hline & & $\mathrm{E}_{2} \downarrow$ & {$[9,10]$} \\
\hline & & $\mathrm{P}_{4}$ & {$[13]$} \\
\hline & & $\mathrm{E}_{2} \downarrow+\mathrm{P}_{4}$ & [13] \\
\hline \multirow{3}{*}{ WNT5A } & Function & Uterine wall morphogenesis & {$[19]$} \\
\hline & \multirow{2}{*}{ Hormonal regulation } & $\mathrm{E}_{2} \downarrow$ & {$[9,10]$} \\
\hline & & $\mathrm{P}_{4}+\mathrm{RU} 486 \uparrow$ & [25] \\
\hline \multirow{4}{*}{ WNT7A } & \multirow{2}{*}{ Function } & Development and functioning of the gonads & [6] \\
\hline & & Postnatal uterine gland morphogenesis and function & [89] \\
\hline & \multirow{2}{*}{ Hormonal regulation } & $\mathrm{E}_{2} \downarrow$ & {$[9,10]$} \\
\hline & & $\mathrm{E}_{2}+\mathrm{P}_{4} \downarrow$ & {$[24]$} \\
\hline \multirow{3}{*}{ CTNNB1 } & Function & Normal functioning of the uterus Endometrial homeostasis & {$[32]$} \\
\hline & \multirow{2}{*}{ Hormonal regulation } & $\mathrm{P}_{4} \uparrow$ & {$[35]$} \\
\hline & & $\mathrm{E}_{2}$ & [35] \\
\hline
\end{tabular}

$\downarrow$ : decreased gene expression; $\uparrow$ : increased gene expression; $\mathrm{E}_{2}$ : estradiol; $\mathrm{P}_{4}$ : progesterone, RU486: antagonist of progesterone receptor.

TABLE 2: Immunohistochemical and molecular markers for ECCs classification.

\begin{tabular}{|c|c|c|c|c|c|}
\hline \multirow{2}{*}{ Method } & \multicolumn{4}{|c|}{ Type of EEC } & \multirow{2}{*}{ References } \\
\hline & Normal & EEAC & ESC & CcEC & \\
\hline \multirow{3}{*}{ IHC } & PTEN & PTEN $\downarrow$ & PTEN - & PTEN - & {$[90]$} \\
\hline & Active $\beta$-catenin & Active $\beta$-catenin + & Active $\beta$-catenin - & Active $\beta$-catenin - & {$[91]$} \\
\hline & p53 & p53-/+ & p53+ & $\mathrm{p} 53+$ & {$[92]$} \\
\hline \multirow{4}{*}{ Real-time PCR } & PTEN & PTEN $\downarrow$ & PTEN & PTEN & {$[90]$} \\
\hline & Survivin & Survivin $\uparrow$ & & & [92] \\
\hline & K-ras & K-ras $\uparrow$ & K-ras $\downarrow$ & K-ras $\downarrow$ & [93] \\
\hline & $\mathrm{p} 27$ & $\mathrm{p} 27 \downarrow$ & & & {$[92]$} \\
\hline
\end{tabular}

+ : protein is present; - : protein is absent; $-/+$ : protein is expressed moderately.

$\downarrow$ : decrease of gene expression; $\uparrow:$ increase of gene expression.

4.2. Wht Gene Expression in Endometrial Cancer. The expression of genes encoding WNT proteins and proteins involved in WNT signaling pathways was found to be changed also in endometrial cancer [12] (Figure 3). The WNT4 mRNA level was lower while WNT2, WNT3, and WNT5A mRNA levels were higher in endometrial carcinoma in comparison to normal endometrium [12]. Also WNT2, WNT3, WNT4, and WNT5A genes expression was higher in normal human primary epithelial and stromal endometrial cultures compared to endometrial carcinoma cell lines, what suggest their participation in endometrial neoplasia [12].

Most of the studies concentrated on WNT7A gene expression. In $63 \%$ patients of one series of endometrial carcinoma, WNT7A gene expression was absent or reduced and negatively correlated with FIGO stage, grade, lymph node metastasis, depth of myometrial invasion, lymph vascular space involvement, and peritoneal cytology [28]. In large-scale population study on 244 EEC patients, WNT7A overexpression was found in most cases of endometrial cancer in comparison with normal endometrium and benign endometrial lesion [46]. However, negative expression of WNT7A gene correlated positively with overall survival and disease-free survival of endometrial cancer [46].

In the Ishikawa cell line model of endometrial adenocarcinoma, estrogen receptors were probably involved [47] in the downregulation of WNT7A expression mediated by estradiol [48]. Moreover, WNT7A and WNT7B genes expression was increased in endometrial carcinoma cell lines and normal endometrial tissues as compared with primary cultures of human endometrial cells [12].

WNT10A and WNT10B proteins have been implicated in estrogen-related carcinogenesis of endometrial cancer. The amount of WNT10B protein was higher in endometrial cancer than in hyperplastic and normal endometrium as determined by Western blot technique [49]. In early stages of endometrial cancer, the expression of WNT10B was higher than in later stages. WNT10B proteins were mainly detected in patients with the cancer of endometrioid type, who had high graded and advanced-staged tumor without lymph node metastasis [49]. This clinical study was partially confirmed by 


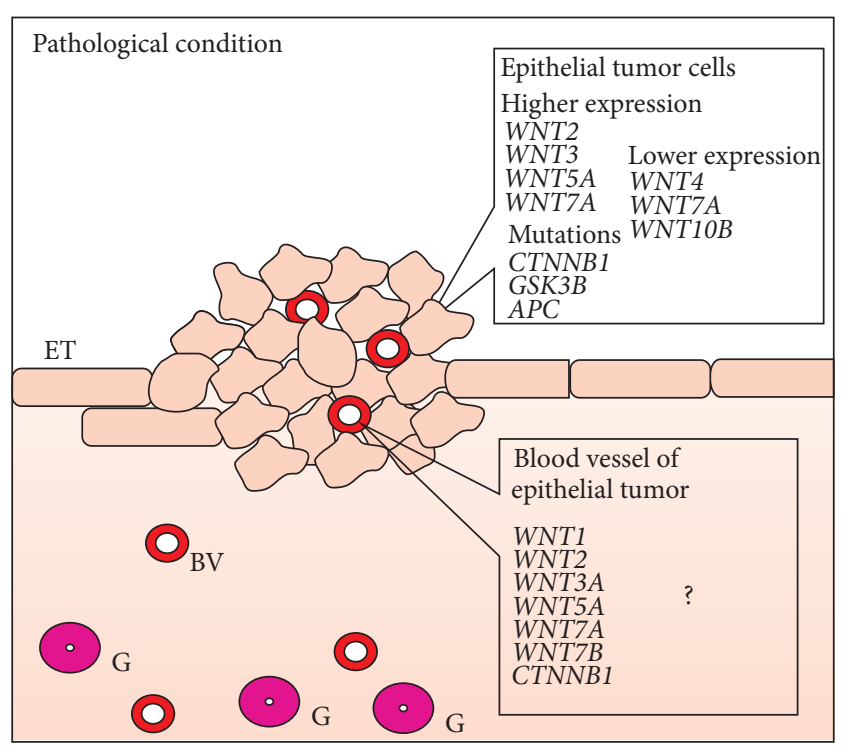

FIGURE 3: Expression of WNT genes in endometrial cancer. ET: epithelial tumor; BV: blood vessel; G: glands.

results of the in vitro investigations. WNT10A gene expression was decreased in endometrial HEC1B and AN3CA cell lines while WNT10B was increased in Ishikawa cell lines [50].

Mutations of $\beta$-catenin gene (CTNNB1) were found in many endometrial cancers [51]. According to various reports, 10 to $45 \%$ of endometrial cancers present missense mutation of CTNNB1 [50]. Endometrial tumors with mutation in exon 3 on serine/threonine residue showed predominant nuclear $\beta$-catenin accumulation. In this case, blockage of the process of $\beta$-catenin degradation results from the lack of its phosphorylation [36, 52, 53]. In rat gliomas [54], human glioblastomas [55], and medulloblastomas [56], nuclear accumulation of $\beta$-catenin was observed in endothelial cells of neovessels. Beta-catenin accumulation was observed in the nucleus of malignant changed endometrial cells $[36,52,53]$. However, as far as we know the presence of $\beta$-catenin was previously not shown in tumor vascular endothelial cells (Figure 4). However, $\beta$-catenin membranous immunoreactivity associated with E-cadherin decreased during transformation of normal endometrium through atypical endometrial hyperplasia to endometrial cancer in parallel with decreased E-cadherin expression in endometrial cancer [57]. CTNNB1 mutation is observed mainly in endometrioid endometrial cancer [5759].

Mutations in KRAS and/or CTNNB1, GSK-3 $\beta$, and APC gene are recognized as major alterations in type I endometrial cancer [50]. Upregulation of estrogen receptor signaling causes endometrial hyperplasia and can be a reason of endometrial cancer [29]. WNT signaling activation leads to endometrial and myometrial hyperplasia [32, 60, 61], squamous cell metaplasia without malignant transformation [62], mesenchymal tumors, and endometrial sarcomas [32, 61] in transgenic mouse [62].

DKK1 was highly expressed in benign endometrial tissue and downregulated in endometrial cancer [63]. Treatment of Ishikawa cell line with DKK1 lowered the level of active $\beta$-catenin as the result of Wnt signaling pathway inhibition through binding to LRP5/6 [63]. DKK1 is positively correlated with histological differentiation and clinical stage of endometrial cancer [63]. DKK3 gene expression was found to be decreased in endometrial cancer. It correlated with advanced stage and high risk clinicopathological factors [51]. High expression of $D k k 3$ gene reduced motility and proliferation of the cells in in vitro experiments [51].

\section{Crosstalk of WNT Proteins and Other Factors in Endometrial Angiogenesis}

5.1. Angiogenesis in Endometrium. Vascular system is a network of arteries, capillaries, and veins for transport of gases and macromolecules. Vasculogenesis is a process of de novo formation of capillary bed through differentiation, proliferation, and migration of precursor cells (angioblasts) [64]. Formation of new blood vessels from already existing capillaries is called angiogenesis [65]. Angiogenesis is a twostep, physiological process essential for proper endometrial functioning [66]. Blood vessels have to be repaired after menstrual phase of the menstrual cycle [66]. Capillaries grow, mature, and coil during the proliferative and secretory phase [66], when endometrial blood flow and permeability of endometrial microvessels become rapidly increased by high levels of estrogens at the late phase of cycle [67]. It is highly probable that vessel growth in human endometrium occurs by nonsprouting mechanism, elongation in response to metabolic demands of surrounding cells [68] and intense hypoxia in the luminal portion of the endometrium on day 2 of the cycle, with negligible detection by d5 [69]. Endothelial cells which form capillary bed are under influence of (i) factors produced by surrounding tissue [65] and/or (ii) angiogenic factors that circulate in blood and their levels fluctuate during menstrual cycle [70]. Growth factors (VEGF, EGF, FGF, NP-1, and angiopoietin) and their receptors (VEGFR, EGFR, FGFR, and IGFR) can both positively or negatively influence this process. The common denominator for the process of angiogenesis occurring in the endometrium is hypoxic environment and hypoxia inducible factor (HIF) stimulation of VEGF expression [71].

5.2. Participation of WNT Proteins in Blood Vessel Formation. Participation of WNT proteins in the process of differentiation of cells of hematopoietic and endothelial cell lineage as well as vasculogenesis and angiogenesis is apparent [72]. It has been demonstrated that sustained WNT pathway activation can be utilized to generate endothelial progenitors from mesodermal lineage of embryonic stem cells in in vitro conditions [73]. Moreover, coculture of human embryonic stem cells with Wnt1-overexpressing cells accelerated differentiation of mesoderm germ layer into hematoendothelial cells via activation of canonical WNT signaling [74]. Presence of WNT1 upregulated $\mathrm{WNT} / \beta$-catenin signaling, bovine aortic endothelial cells proliferation, and capillary stability under in vitro conditions [75]. On the other hand, WNT1 was found to inhibit proliferation of endothelial cells [76].

The role of the WNT2 protein in angiogenesis is less clear. Increased expression of WNT2 protein and FZD-5 receptor 


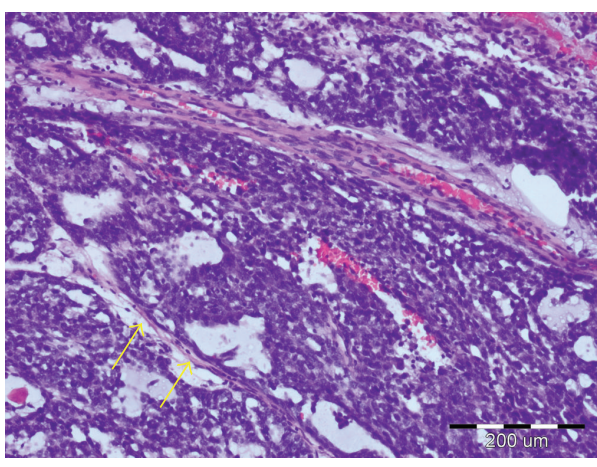

(a)

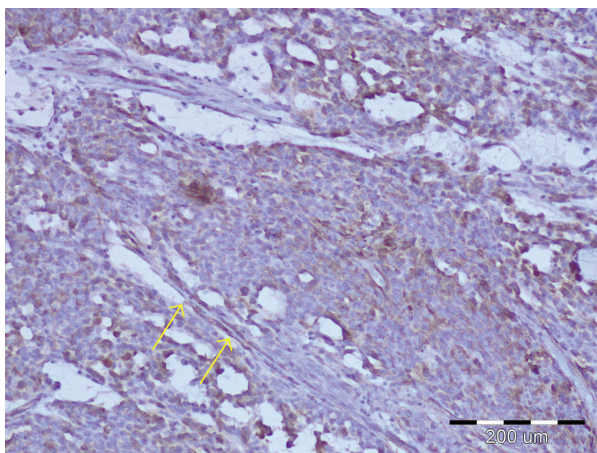

(c)

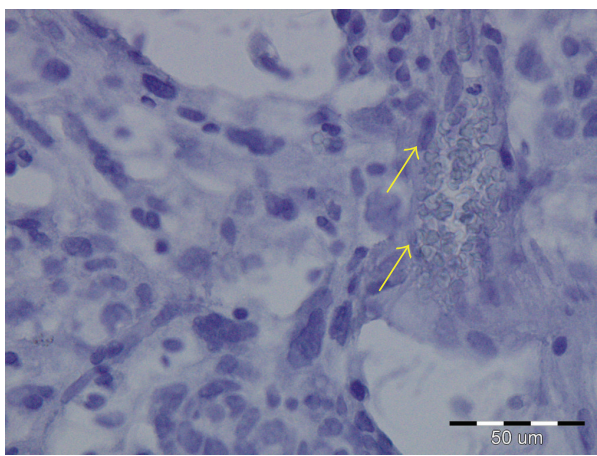

(e)

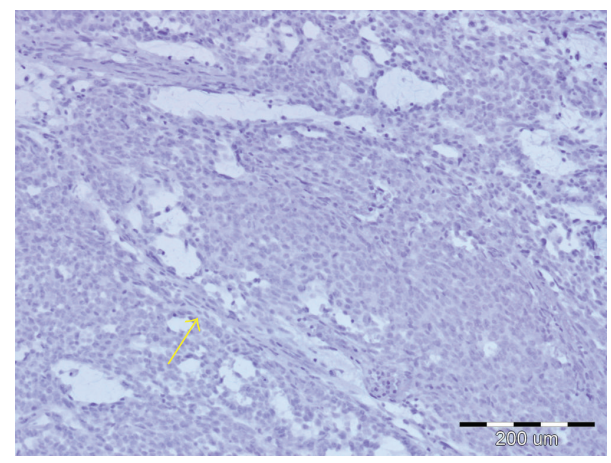

(b)

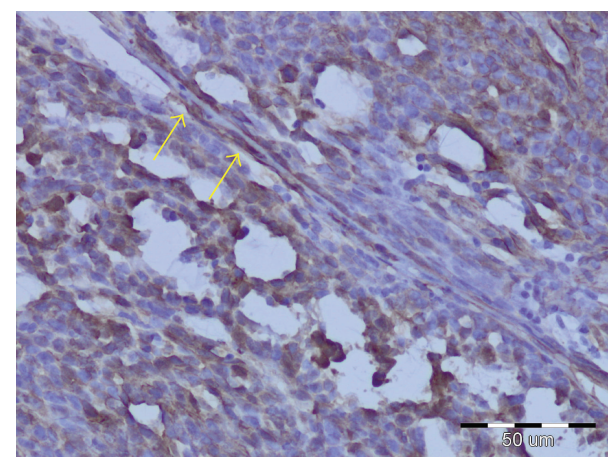

(d)

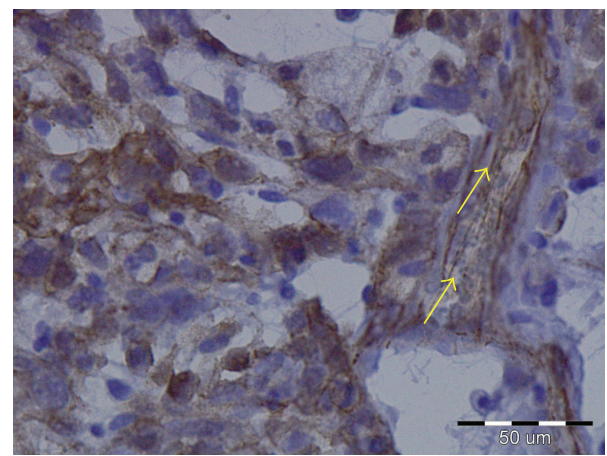

(f)

FIGURE 4: Examples of immunohistochemical staining confirming presence of $\beta$-catenin in adenocarcinoma endometrioid (G3) cells and tumor vascular endothelial cells (arrow). Hematoxylin-eosin staining (a); negative controls in magnification $\times 20$ (b) and $\times 40$ (e); positive staining (BD Transduction Laboratories; Cat. number 610153) in magnification $\times 20$ (c) and $\times 40$ (d, f).

caused defects in the vasculature of murine placenta and changed blood flow in the mouse yolk sac $[77,78]$ as a reduced number of the fetal capillaries were observed [79]. However, expression of WNT2 gene had no impact on $\mathrm{WNT} / \beta$-catenin signaling activation, endothelial cells proliferation $[72,75]$, or capillary length [75]. Differentiation of endothelial cells from mouse embryonic stem cells is suspected to be controlled by Wnt2 and Wnt11 [39].

WNT3A was shown to be direct, VEGF-independent, inducer of endothelial cell proliferation $[72,80]$ and migration [80].

WNT5A is required for endothelial differentiation of embryonic stem cells and transformation of mouse embryonic stem cells into immature endothelial progenitor cells, taking part in healing process of damaged endothelium [39]. Acting on endothelial cells through autocrine regulation [81], WNT5A can decrease cell number and capillary length. However, these effects were not observed after activation of $\mathrm{WNT} / \beta$-catenin signaling [75]. Moreover, WNT5A protein did not stimulate human umbilical vein endothelial cells (HUVEC) migration and proliferation [75]. Wnt5a and Wnt10b induced FZD-5-mediated angiogenesis in a mice yolk sac [79].

WNT7 proteins were shown to promote normal angiogenesis in ventral regions of the CNS in mouse [82]. Specifically Wnt7a but not VEGF promotes migration and stimulates expression of blood-brain barrier specific transporters of glucose (GLUT-1) in mouse brain endothelial cell line [82]. 
Moreover, in $W n t 7 b$ gene deficient mice, loss of $W n t 7 b$ gene resulted in defective smooth muscle component of the major pulmonary vessel differentiation, degradation of vessel's wall, and perinatal hemorrhage [83].

Inhibition of the expression of CTNNB1 gene in endothelial cells affected the formation of vasculature of head of mouse embryos, large vitelline and umbilical vessels, and the vasculature of the placenta [84]. As a result of $\beta$-catenin absence, significant reduction in cell junctions organization and hemorrhage was observed [84].

5.3. Hypothetical Involvement of the Wnt/ $\beta$-Catenin Pathway in Endometrial Angiogenesis. Data provided in the proceeding chapter clearly indicate the participation of WNT proteins in the recruitment, proliferation, and migration of endothelial cells in healthy subjects and cancer patients. In the endometrium, development of the vascular network occurs simultaneously with epithelial and stromal cells expansion, expression, and influence of angiogenic factors that circulate in blood and fluctuate in menstrual cycle phase-dependent manner [70]. Regulation of endothelial cell growth and fate was shown to be regulated by reciprocal interactions between mesenchymal and endothelial cells [81]. Even if estradiol was shown to inhibit angiogenesis under in vivo conditions [85], this effect was not caused by direct action on endothelial cells because they do not have estrogen receptors [86]. Therefore, they cannot respond to this potential inhibitor of angiogenesis. Thus, it is highly probable that in endometrium capillaries are under influence of other external factors which compensate or antagonize the influence of estradiol. We suggest that WNT proteins are perfect candidate to be such a mediator.

We can hypothesize (Figure 5) that it might be probable that in physiological condition WNT5A can participate in endothelium recovery, rather than angiogenesis process, as it takes part in healing of the damaged endothelium [39], but not in proliferation and migration of the endothelial cells [81] or increasing capillary length [75]. WNT7A might be chemoattractant for endothelial cells in the process of physiological endometrial angiogenesis, as it is a factor of epithelial origin. WNT7A gene expression was upregulated during proliferative phase of the estrous cycle and downregulated in the secretory phase [26]. $\beta$-catenin can function in the endometrium either directly on endothelial cells or indirectly through its action on endometrial cells where it promotes the expression of VEGF [87] or endothelin 1 [39]. However, this hypothesis requires experimental confirmation.

\section{Conclusions and Future Perspectives}

The participation of WNT proteins, $\beta$-catenin, and inhibitors and inducers of WNT signaling in the process of endometrial angiogenesis is largely unknown. The main task which should be now undertaken should concentrate on defining which WNT, receptors, inhibitors, and signaling pathway are activated in the endothelial cells of the blood vessel of the endometrium. The spatiotemporal pattern of expression of elements of WNT signaling system should also be established. Differences in normal and pathological state should be also

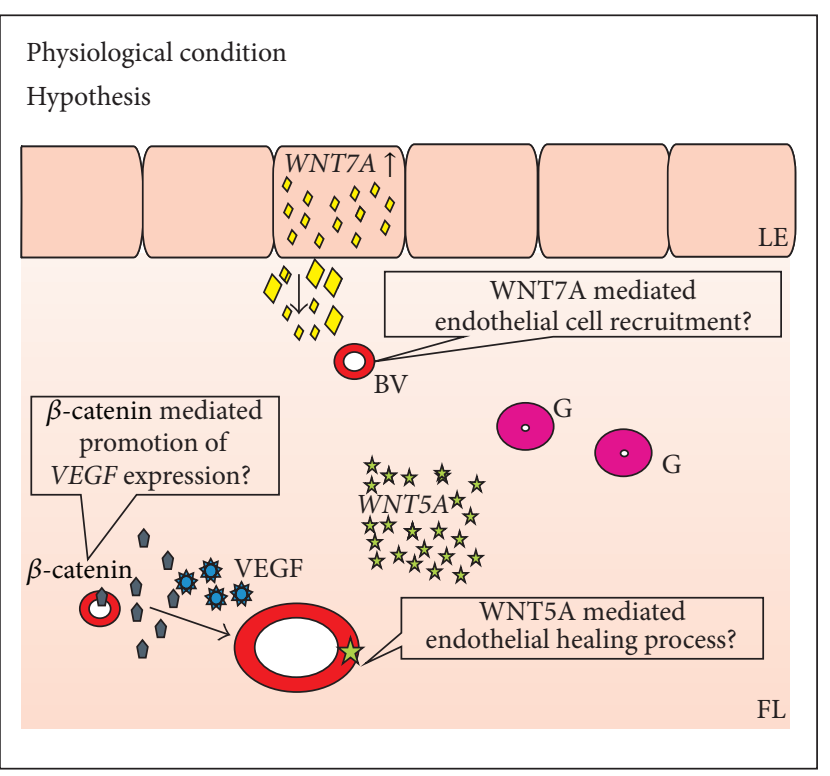

FIGURE 5: Hypothetical involvement of WNT and $\beta$-catenin proteins in endometrial angiogenesis. LE: luminal epithelium; FL: functional layer; ET: epithelial tumor; BV: blood vessel; G: glands.

considered. Conducting this research will help to determine the angiogenic potential of the WNT family of proteins, will allow for a better understanding of the mechanism of formation of vessels in the endometrium, and will help to determine whether WNT proteins can be potential target for antiangiogenic therapy directed mainly against transcription factors as, for example, $\beta$-catenin. We are aware that our hypothesis does not present the experimentally verified information. However, we believe that our suggestion will contribute to the discussion and to some extent the development of research on the role of WNT proteins in the formation of blood vessels in the dynamically changing uterus.

\section{Conflict of Interests}

The authors declare that there is no conflict of interests regarding the publication of this paper.

\section{Authors' Contribution}

Jolanta Kiewisz and Tomasz Wasniewski equally contributed to this paper.

\section{Acknowledgments}

The publication of the review is partially financed from statutory grant from Faculty of Medical Science, University of Warmia and Mazury (528-1501-0801). The authors are grateful to Mrs. M. Zalewska-Ludzia for technical assistance and Mrs. M. Borkowska for editorial assistance. 


\section{References}

[1] K. M. Cadigan and R. Nusse, "Wnt signaling: a common theme in animal development," Genes \& Development, vol. 11, no. 24, pp. 3286-3305, 1997.

[2] A. Kikuchi, H. Yamamoto, and S. Kishida, "Multiplicity of the interactions of Wnt proteins and their receptors," Cellular Signalling, vol. 19, no. 4, pp. 659-671, 2007.

[3] http://web.stanford.edu/group/nusselab/cgi-bin/wnt/.

[4] M. A. Torres, J. A. Yang-Snyder, S. M. Purcell, A. A. DeMarais, L. L. McGrew, and R. T. Moon, "Activities of the Wnt-1 class of secreted signaling factors are antagonized by the Wnt-5A class and by a dominant negative cadherin in early Xenopus development," The Journal of Cell Biology, vol. 133, no. 5, pp. 1123-1137, 1996.

[5] D. Strutt, "Frizzled signalling and cell polarisation in Drosophila and vertebrates," Development, vol. 130, no. 19, pp. 4501-4513, 2003.

[6] C. Miller and D. A. Sassoon, "Wnt-7a maintains appropriate uterine patterning during the development of the mouse female reproductive tract," Development, vol. 125, no. 16, pp. 3201-3211, 1998.

[7] M. Mericskay, J. Kitajewski, and D. Sassoon, "Wnt5a is required for proper epithelial-mesenchymal interactions in the uterus," Development, vol. 131, no. 9, pp. 2061-2072, 2004.

[8] O. A. Mohamed, M. Jonnaert, C. Labelle-Dumais, K. Kuroda, H. J. Clarke, and D. Dufort, "Uterine Wnt/beta-catenin signaling is required for implantation," Proceedings of the National Academy of Sciences of the United States of America, vol. 102, no. 24, pp. 8579-8584, 2005.

[9] F. F. Bartol, A. A. Wiley, and C. A. Bagnell, "Uterine development and endometrial programming," Society of Reproduction and Fertility supplement, vol. 62, pp. 113-130, 2006.

[10] J. C. Chen, A. A. Wiley, T.-Y. Ho et al., "Transient estrogen exposure from birth affects uterine expression of developmental markers in neonatal gilts with lasting consequences in pregnant adults," Reproduction, vol. 139, no. 3, pp. 623-630, 2010.

[11] S. Tulac, N. R. Nayak, L. C. Kao et al., "Identification, characterization, and regulation of the canonical Wnt signaling pathway in human endometrium," Journal of Clinical Endocrinology and Metabolism, vol. 88, no. 8, pp. 3860-3866, 2003.

[12] T. D. Bui, L. Zhang, M. C. P. Rees, R. Bicknell, and A. L. Harris, "Expression and hormone regulation of Wnt2, 3, 4, 5a, $7 \mathrm{a}, 7 \mathrm{~b}$ and $10 \mathrm{~b}$ in normal human endometrium and endometrial carcinoma," British Journal of Cancer, vol. 75, no. 8, pp. 1131-1136, 1997.

[13] K. Hayashi, R. C. Burghardt, F. W. Bazer, and T. E. Spencer, "WNTs in the ovine uterus: potential regulation of periimplantation ovine conceptus development," Endocrinology, vol. 148, no. 7, pp. 3496-3506, 2007.

[14] M. O. Atli, A. Guzeloglu, and D. A. Dinc, "Expression of wingless type (WNT) genes and their antagonists at mRNA levels in equine endometrium during the estrous cycle and early pregnancy," Animal Reproduction Science, vol. 125, no. 1-4, pp. 94-102, 2011.

[15] J. Kiewisz, M. M. Kaczmarek, A. Andronowska, A. Blitek, and A. J. Ziecik, "Gene expression of WNTs, $\beta$-catenin and Ecadherin during the periimplantation period of pregnancy in pigs-involvement of steroid hormones," Theriogenology, vol. 76, no. 4, pp. 687-699, 2011.

[16] J. Kiewisz, M. M. Kaczmarek, E. Morawska, A. Blitek, W. Kapelanski, and A. J. Ziecik, "Estrus synchronization affects
WNT signaling in the porcine reproductive tract and embryos," Theriogenology, vol. 76, no. 9, pp. 1684-1694, 2011.

[17] K. Stark, S. Vainio, G. Vassileva, and A. P. McMahon, "Epithelial transformation metanephric mesenchyme in the developing kidney regulated by Wnt-4," Nature, vol. 372, no. 6507, pp. 679683, 1994.

[18] S. Vainio, M. Heikkilä, A. Kispert, N. Chin, and A. P. McMahon, "Female development in mammals is regulated by Wnt-4 signalling," Nature, vol. 397, no. 6718, pp. 405-409, 1999.

[19] X. Hou, Y. Tan, M. Li, S. K. Dey, and S. K. Das, "Canonical Wnt signaling is critical to estrogen-mediated uterine growth," Molecular Endocrinology, vol. 18, no. 12, pp. 3035-3049, 2004.

[20] T. P. Yamaguchi, A. Bradley, A. P. McMahon, and S. Jones, "A Wnt5a pathway underlies outgrowth of multiple structures in the vertebrate embryo," Development, vol. 126, no. 6, pp. 1211$1223,1999$.

[21] M. Heikkil, H. Peltoketo, and S. Vainio, "Wnts and the female reproductive system," Journal of Experimental Zoology, vol. 290, no. 6, pp. 616-623, 2001.

[22] A. Pavlova, E. Boutin, G. Cunha, and D. Sassoon, "Msxl (Hox7.1) in the adult mouse uterus: cellular interactions underlying regulation of expression," Development, vol. 120, no. 2, pp. 335345, 1994.

[23] C. Miller, A. Pavlova, and D. A. Sassoon, "Differential expression patterns of Wnt genes in the murine female reproductive tract during development and the estrous cycle," Mechanisms of Development, vol. 76, no. 1-2, pp. 91-99, 1998.

[24] K. Hayashi, D. W. Erikson, S. A. Tilford et al., "Wnt genes in the mouse uterus: potential regulation of implantation," Biology of Reproduction, vol. 80, no. 5, pp. 989-1000, 2009.

[25] M. C. Satterfield, G. Song, K. Hayashi, F. W. Bazer, and T. E. Spencer, "Progesterone regulation of the endometrial WNT system in the ovine uterus," Reproduction, Fertility and Development, vol. 20, no. 8, pp. 935-946, 2008.

[26] X. Fan, S. Krieg, J. Y. Hwang et al., "Dynamic regulation of Wnt7a expression in the primate endometrium: Implications for postmenstrual regeneration and secretory transformation," Endocrinology, vol. 153, no. 3, pp. 1063-1069, 2012.

[27] R. Gaetje, U. Holtrich, T. Karn et al., "Characterization of WNT7A expression in human endometrium and endometriotic lesions," Fertility and Sterility, vol. 88, no. 6, pp. 1534-1540, 2007.

[28] C. Peng, X. Zhang, Y. Wang, L. Li, Q. Wang, and J. Zheng, "Expression and prognostic significance of Wnt7a in human endometrial carcinoma," Obstetrics and Gynecology International, vol. 2012, Article ID 134962, 8 pages, 2012.

[29] Y. Wang, P. Hanifi-Moghaddam, E. E. Hanekamp et al., "Progesterone inhibition of Wnt/ $\beta$-catenin signaling in normal endometrium and endometrial cancer," Clinical Cancer Research, vol. 15, no. 18, pp. 5784-5793, 2009.

[30] M. K. Oehler, I. Z. MacKenzie, D. Wallwiener, R. Bicknell, and M. C. Rees, "Wnt-7a is upregulated by norethisterone in human endometrial epithelial cells: a possible mechanism by which progestogens reduce the risk of estrogen-induced endometrial neoplasia," Cancer Letters, vol. 186, no. 1, pp. 75-81, 2002.

[31] H. Aberle, S. Butz, J. Stappert, H. Weissig, R. Kemler, and H. Hoschuetzky, "Assembly of the cadherin-catenin complex in vitro with recombinant proteins," Journal of Cell Science, vol. 107, no. 12, pp. 3655-3663, 1994.

[32] J.-W. Jeong, H. S. Lee, H. L. Franco et al., "Beta-catenin mediates glandular formation and dysregulation of beta-catenin induces hyperplasia formation in the murine uterus," Oncogene, vol. 28, no. 1, pp. 31-40, 2009. 
[33] S. Tabibzadeh, A. Babaknia, Q. F. Kong et al., "Menstruation is associated with disordered expression of desmoplakin I/II and cadherin/catenins and conversion of F- to G-actin in endometrial epithelium," Human Reproduction, vol. 10, no. 4, pp. 776-784, 1995.

[34] J. Fujimoto, S. Ichigo, M. Hori, and T. Tamaya, "Alteration of E-cadherin, alpha- and beta-catenin mRNA expression in human uterine endometrium during the menstrual cycle," Gynecological Endocrinology, vol. 10, no. 3, pp. 187-191, 1996.

[35] G. T. C. Chen, S. Getsios, and C. D. MacCalman, "Progesterone regulates $\beta$-catenin mRNA levels in human endometrial stromal cells in vitro," Endocrine, vol. 9, no. 3, pp. 263-267, 1998.

[36] H. Nei, T. Saito, H. Yamasaki, H. Mizumoto, E. Ito, and R. Kudo, "Nuclear localization of $\beta$-catenin in normal and carcinogenic endometrium," Molecular Carcinogenesis, vol. 25, no. 3, pp. 207218, 1999.

[37] A. G. Gunin, V. U. Emelianov, I. U. Mironkin, M. P. Morozov, and A. S. Tolmachev, "Lithium treatment enhances estradiolinduced proliferation and hyperplasia formation in the uterus of mice," The European Journal of Obstetrics Gynecology and Reproductive Biology, vol. 114, no. 1, pp. 83-91, 2004.

[38] A. J. Polotsky, L. Zhu, N. Santoro, and J. W. Pollard, "Lithium chloride treatment induces epithelial cell proliferation in xenografted human endometrium," Human Reproduction, vol. 24, no. 8, pp. 1960-1967, 2009.

[39] D.-H. Yang, J.-Y. Yoon, S.-H. Lee et al., "Wnt5a is required for endothelial differentiation of embryonic stem cells and vascularization via pathways involving both $\mathrm{Wnt} / \beta$-Catenin and protein kinase C $\alpha$," Circulation Research, vol. 104, no. 3, pp. 372-379, 2009.

[40] A. Jemal, R. Siegel, and T. Murray, “Cancer statistics, 2011," CA: A Cancer Journal for Clinicians, vol. 61, no. 4, pp. 212-236, 2011.

[41] G. D’Andrilli, A. Bovicelli, M. G. Paggi, and A. Giordano, "New insights in endometrial carcinogenesis," Journal of Cellular Physiology, vol. 227, no. 7, pp. 2842-2846, 2012.

[42] A. J. Ryan, B. Susil, T. W. Jobling, and M. K. Oehler, "Endometrial cancer," Cell and Tissue Research, vol. 322, no. 1, pp. 53-61, 2005.

[43] J. Prat, A. Gallardo, M. Cuatrecasas, and L. Catasús, "Endometrial carcinoma: pathology and genetics," Pathology, vol. 39, no. 1, pp. 72-87, 2007.

[44] W. T. Creasman, F. Odicino, P. Mausinneuve, M. A. Quinn, U. Beller, and J. L. Benedet, "Carcinoma of the corpus uteri. FIGO Annual Report," International Journal of Gynaecology \& Obstetrics, vol. 26, no. 95, supplement 1, pp. 105-143, 2006.

[45] E. Hiroki, J.-I. Akahira, F. Suzuki et al., "Changes in microRNA expression levels correlate with clinicopathological features and prognoses in endometrial serous adenocarcinomas," Cancer Science, vol. 101, no. 1, pp. 241-249, 2010.

[46] Y. Liu, F. Meng, Y. Xu et al., "Overexpression of Wnt7a is associated with tumor progression and unfavorable prognosis in endometrial cancer," International Journal of Gynecological Cancer, vol. 23, no. 2, pp. 304-311, 2013.

[47] J. Wagner and L. Lehmann, "Estrogens modulate the gene expression of Wnt-7a in cultured endometrial adenocarcinoma cells," Molecular Nutrition and Food Research, vol. 50, no. 4-5, pp. 368-372, 2006.

[48] H. Newill, R. Loske, J. Wagner, C. Johannes, R. L. Lorenz, and L. Lehmann, "Oxidation products of stigmasterol interfere with the action of the female sex hormone 17beta-estradiol in cultured human breast and endometrium cell lines," Molecular Nutrition and Food Research, vol. 51, no. 7, pp. 888-898, 2007.
[49] H. Chen, Y. Wang, and F. Xue, "Expression and the clinical significance of Wnt10a and Wnt10b in endometrial cancer are associated with the Wnt/ $\beta$-catenin pathway," Oncology Reports, vol. 29, no. 2, pp. 507-514, 2013.

[50] Y. Wang, M. van der Zee, R. Fodde, and L. J. Blok, "Wnt/Bcatenin and sex hormone signaling in endometrial homeostasis and cancer," Oncotarget, vol. 1, no. 7, pp. 674-684, 2010.

[51] T. H. Dellinger, K. Planutis, K. S. Tewari, and R. F. Holcombe, "Role of canonical Wnt signaling in endometrial carcinogenesis," Expert Review of Anticancer Therapy, vol. 12, no. 1, pp. 51-62, 2012.

[52] T. Fukuchi, M. Sakamoto, H. Tsuda, K. Maruyama, S. Nozawa, and S. Hirohashi, " $\beta$-catenin mutation in carcinoma of the uterine endometrium," Cancer Research, vol. 58, no. 16, pp. 3526-3528, 1998.

[53] T. Ikeda, K. Yoshinaga, S. Semba, E. Kondo, H. Ohmori, and A. Horii, "Mutational analysis of the CTNNB1 ( $\beta$-catenin) gene in human endometrial cancer: frequent mutations at codon 34 that cause nuclear accumulation," Oncology Reports, vol. 7, no. 2, pp. 323-326, 2000.

[54] H. Yano, A. Hara, J. Shinoda et al., "Immunohistochemical analysis of $\beta$-catenin in $N$-ethyl- $N$-nitrosourea-induced rat gliomas: implications in regulation of angiogenesis," Neurological Research, vol. 22, no. 5, pp. 527-532, 2000.

[55] H. Yano, A. Hara, K. Takenaka et al., "Differential expression of $\beta$-catenin in human glioblastoma multiforme and normal brain tissue," Neurological Research, vol. 22, no. 7, pp. 650-656, 2000.

[56] C. G. Eberhart, T. Tihan, and P. C. Burger, "Nuclear localization and mutation of beta-catenin in medulloblastomas," Journal of Neuropathology and Experimental Neurology, vol. 59, no. 4, pp. 333-337, 2000.

[57] M. Saegusa, M. Hashimura, T. Yoshida, and I. Okayasu, “ $\beta$ catenin mutations and aberrant nuclear expression during endometrial tumorigenesis," British Journal of Cancer, vol. 84, no. 2, pp. 209-217, 2001.

[58] P. W. Schlosshauer, E. C. Pirog, R. L. Levine, and L. H. Ellenson, "Mutational analysis of the CTNNB1 and APC genes in uterine endometrioid carcinoma," Modern Pathology, vol. 13, no. 10, pp. 1066-1071, 2000.

[59] G. Moreno-Bueno, D. Hardisson, C. Sánchez et al., "Abnormalities of the APC/beta-catenin pathway in endometrial cancer," Oncogene, vol. 21, no. 52, pp. 7981-7990, 2002.

[60] Q. Li, A. Kannan, W. Wang et al., "Bone morphogenetic protein 2 functions via a conserved signaling pathway involving Wnt4 to regulate uterine decidualization in the mouse and the human," The Journal of Biological Chemistry, vol. 282, no. 43, pp. 31725-31732, 2007.

[61] P. S. Tanwar, H.-J. Lee, L. Zhang et al., "Constitutive activation of beta-catenin in uterine stroma and smooth muscle leads to the development of mesenchymal tumors in mice," Biology of Reproduction, vol. 81, no. 3, pp. 545-552, 2009.

[62] M. van der Zee, Y. Jia, Y. Wang et al., "Alterations in Wnt- $\beta$ catenin and Pten signalling play distinct roles in endometrial cancer initiation and progression," The Journal of Pathology, vol. 230, no. 1, pp. 48-58, 2013.

[63] N. Yi, Q.-P. Liao, T. Li, and Y. Xiong, "Novel expression profiles and invasiveness-related biology function of DKK1 in endometrial carcinoma," Oncology Reports, vol. 21, no. 6, pp. 1421-1427, 2009.

[64] Y. Kubota, "Tumor angiogenesis and anti-angiogenic therapy," The Keio Journal of Medicine, vol. 61, no. 2, pp. 47-56, 2012. 
[65] E. Dejana, "The role of wnt signaling in physiological and pathological angiogenesis," Circulation Research, vol. 107, no. 8, pp. 943-952, 2010.

[66] R. Demir, A. Yaba, and B. Huppertz, "Vasculogenesis and angiogenesis in the endometrium during menstrual cycle and implantation," Acta Histochemica, vol. 112, no. 3, pp. 203-214, 2010.

[67] R. D. Koos, "Minireview: putting physiology back into estrogens' mechanism of action," Endocrinology, vol. 152, no. 12, pp. 4481-4488, 2011.

[68] C. E. Gargett and P. A. W. Rogers, "Human endometrial angiogenesis," Reproduction, vol. 121, no. 2, pp. 181-186, 2001.

[69] H. O. D. Critchley, J. Osei, T. A. Henderson et al., "Hypoxiainducible factor-1 expression in human endometrium and its regulation by prostaglandin E-series prostanoid receptor 2 (EP2)," Endocrinology, vol. 147, no. 2, pp. 744-753, 2006.

[70] L. G. Nardo, "Vascular endothelial growth factor expression in the endometrium during the menstrual cycle, implantation window and early pregnancy," Current Opinion in Obstetrics \& Gynecology, vol. 17, no. 4, pp. 419-423, 2005.

[71] P. Carmeliet, L. Moons, and D. Collen, "Mouse models of angiogenesis, arterial stenosis, atherosclerosis and hemostasis," Cardiovascular Research, vol. 39, no. 1, pp. 8-33, 1998.

[72] T. N. H. Masckauchán, C. J. Shawber, Y. Funahashi, C.-M. Li, and J. Kitajewski, "Wnt/ $\beta$-catenin signaling induces proliferation, survival and interleukin-8 in human endothelial cells," Angiogenesis, vol. 8, no. 1, pp. 43-51, 2005.

[73] M. M. Bakre, A. Hoi, J. C. Y. Mong, Y. Y. Koh, K. Y. Wong, and L. W. Stanton, "Generation of multipotential mesendodermal progenitors from mouse embryonic stem cells via sustained Wnt pathway activation," The Journal of Biological Chemistry, vol. 282, no. 43, pp. 31703-31712, 2007.

[74] P. S. Woll, J. K. Morris, M. S. Painschab et al., "Wnt signaling promotes hematoendothelial cell development from human embryonic stem cells," Blood, vol. 111, no. 1, pp. 122-131, 2008.

[75] A. M. Goodwin, J. Kitajewski, and P. A. D’Amore, "Wntl and Wnt5a affect endothelial proliferation and capillary length; Wnt2 does not," Growth Factors, vol. 25, no. 1, pp. 25-32, 2007.

[76] C.-W. Cheng, S. K. Smith, and D. S. Charnock-Jones, "Wnt1 signaling inhibits human umbilical vein endothelial cell proliferation and alters cell morphology," Experimental Cell Research, vol. 291, no. 2, pp. 415-425, 2003.

[77] S. J. Monkley, S. J. Delaney, D. J. Pennisi, J. H. Christiansen, and B. J. Wainwright, "Targeted disruption of the Wnt2 gene results in placentation defects," Development, vol. 122, no. 11, pp. 33433353, 1996.

[78] X. Ye, Y. Wang, H. Cahill et al., "Norrin, frizzled-4, and Lrp5 signaling in endothelial cells controls a genetic program for retinal vascularization," Cell, vol. 139, no. 2, pp. 285-298, 2009.

[79] T.-O. Ishikawa, Y. Tamai, A. M. Zorn et al., "Mouse Wnt receptor gene Fzd5 is essential for yolk sac and placental angiogenesis," Development, vol. 128, no. 1, pp. 25-33, 2001.

[80] I. Samarzija, P. Sini, T. Schlange, G. MacDonald, and N. E. Hynes, "Wnt3a regulates proliferation and migration of HUVEC via canonical and non-canonical Wnt signaling pathways," Biochemical and Biophysical Research Communications, vol. 386, no. 3, pp. 449-454, 2009.

[81] C.-W. Cheng, J.-C. Yeh, T.-P. Fan, S. K. Smith, and D. S. Charnock-Jones, "Wnt5a-mediated non-canonical Wnt signalling regulates human endothelial cell proliferation and migration," Biochemical and Biophysical Research Communications, vol. 365, no. 2, pp. 285-290, 2008.
[82] R. Daneman, D. Agalliu, L. Zhou, F. Kuhnert, C. J. Kuo, and B. A. Barres, "Wnt/ $\beta$-catenin signaling is required for $\mathrm{CNS}$, but not non-CNS, angiogenesis," Proceedings of the National Academy of Sciences of the United States of America, vol. 106, no. 2, pp. 641646, 2009.

[83] W. Shu, Y. Q. Jiang, M. M. Lu, and E. E. Morrisey, "Wnt7b regulates mesenchymal proliferation and vascular development in the lung," Development, vol. 129, no. 20, pp. 4831-4842, 2002.

[84] A. Cattelino, S. Liebner, R. Gallini et al., "The conditional inactivation of the beta-catenin gene in endothelial cells causes a defective vascular pattern and increased vascular fragility," The Journal of Cell Biology, vol. 162, no. 6, pp. 1111-1122, 2003.

[85] H. Madjar, H. J. Prömpeler, W. Sauerbrei, R. Wolfarth, and A. Pfleiderer, "Color Doppler flow criteria of breast lesions," Ultrasound in Medicine and Biology, vol. 20, no. 9, pp. 849-858, 1994.

[86] M. Perrot-Applanat, M. T. Groyer-Picard, E. Garcia, F. Lorenzo, and E. Milgrom, "Immunocytochemical demonstration of estrogen and progesterone receptors in muscle cells of uterine arteries in rabbits and humans," Endocrinology, vol. 123, no. 3, pp. 1511-1519, 1988.

[87] G. Krikun, F. Schatz, and C. J. Lockwood, "Endometrial angiogenesis: from physiology to pathology," Annals of the New York Academy of Sciences, vol. 1034, pp. 27-35, 2004.

[88] K. Y. Lee, J.-W. Jeong, J. Wang et al., "Bmp2 is critical for the murine uterine decidual response," Molecular and Cellular Biology, vol. 27, no. 15, pp. 5468-5478, 2007.

[89] K. A. Dunlap, J. Filant, K. Hayashi et al., "Postnatal deletion of Wnt7a inhibits uterine gland morphogenesis and compromises adult fertility in mice," Biology of Reproduction, vol. 85, no. 2, pp. 386-396, 2011.

[90] G. L. Mutter, M.-C. Lin, J. T. Fitzgerald et al., "Altered PTEN expression as a diagnostic marker for the earliest endometrial precancers," The Journal of the National Cancer Institute, vol. 92, no. 11, pp. 924-931, 2000.

[91] P. W. Schlosshauer, L. H. Ellenson, and R. A. Soslow, "Betacatenin and E-cadherin expression patterns in high-grade endometrial carcinoma are associated with histological subtype," Modern Pathology, vol. 15, no. 10, pp. 1032-1037, 2002.

[92] S. Erkanli, F. Eren, S. Pekin, and T. Bagis, "BCL-2 and P53 expression in endometrial carcinoma," Journal of Experimental and Clinical Cancer Research, vol. 23, no. 1, pp. 97-103, 2004.

[93] S. F. Lax, B. Kendall, H. Tashiro, R. J. C. Slebos, and L. H. Ellenson, "The frequency of p53, k-ras mutations, and microsatellite instability differs in uterine endometrioid and serous carcinoma," Cancer, vol. 88, no. 4, pp. 814-824, 2000. 


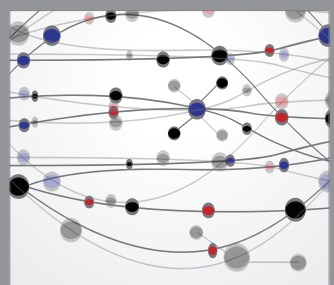

The Scientific World Journal
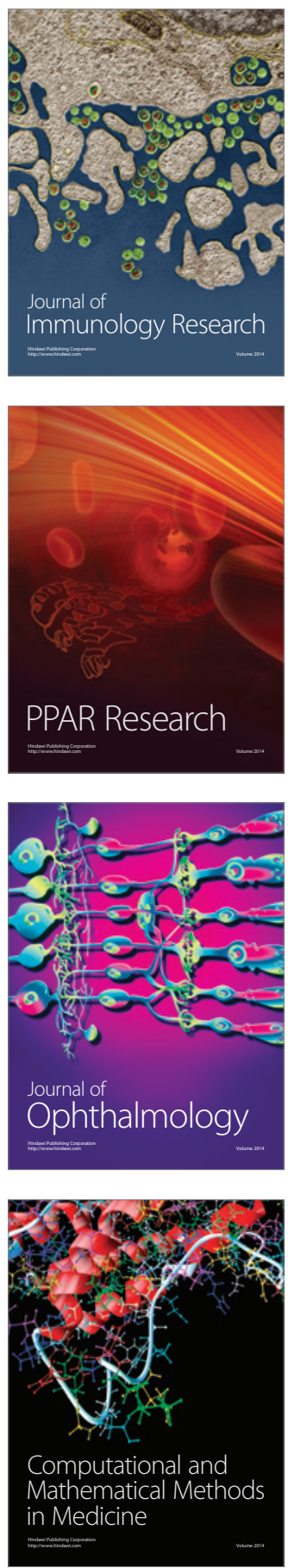

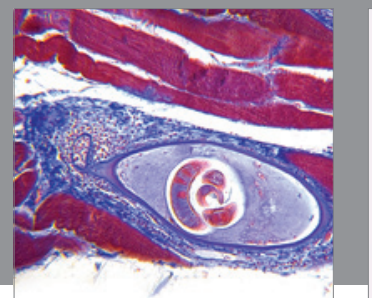

Gastroenterology

Research and Practice
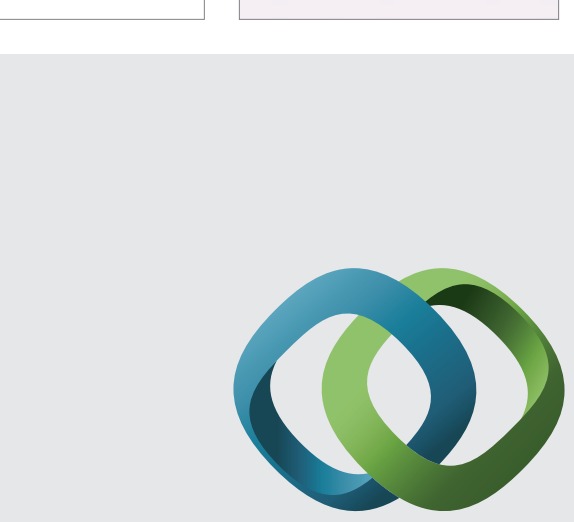

\section{Hindawi}

Submit your manuscripts at

http://www.hindawi.com
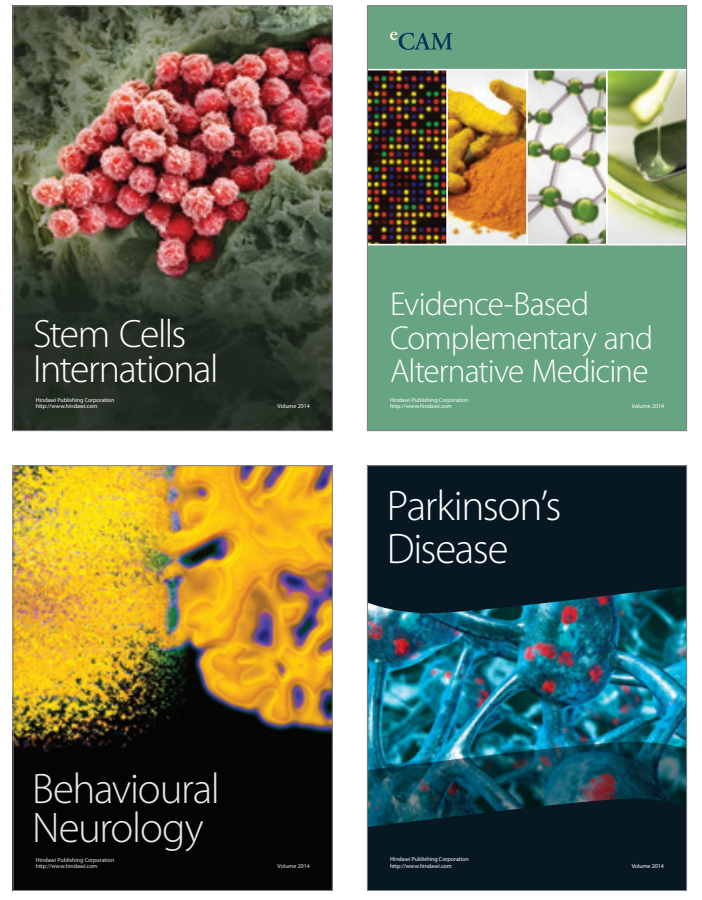
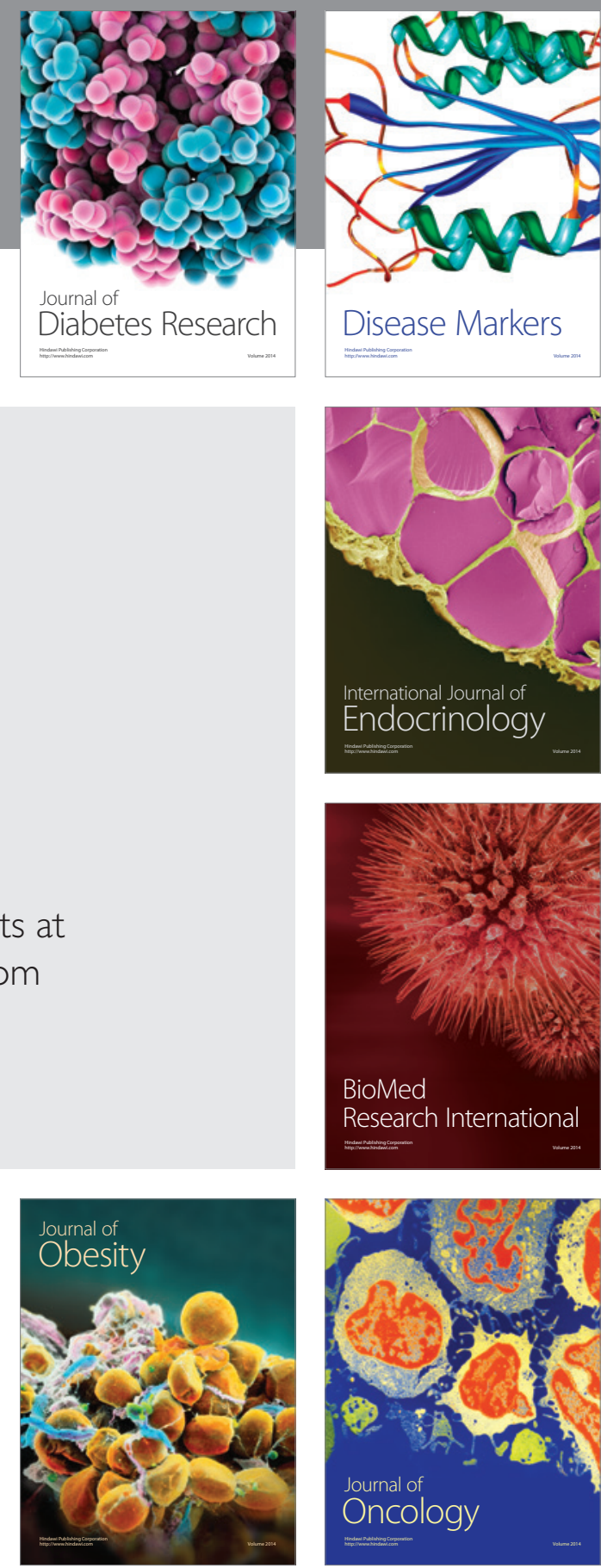

Disease Markers
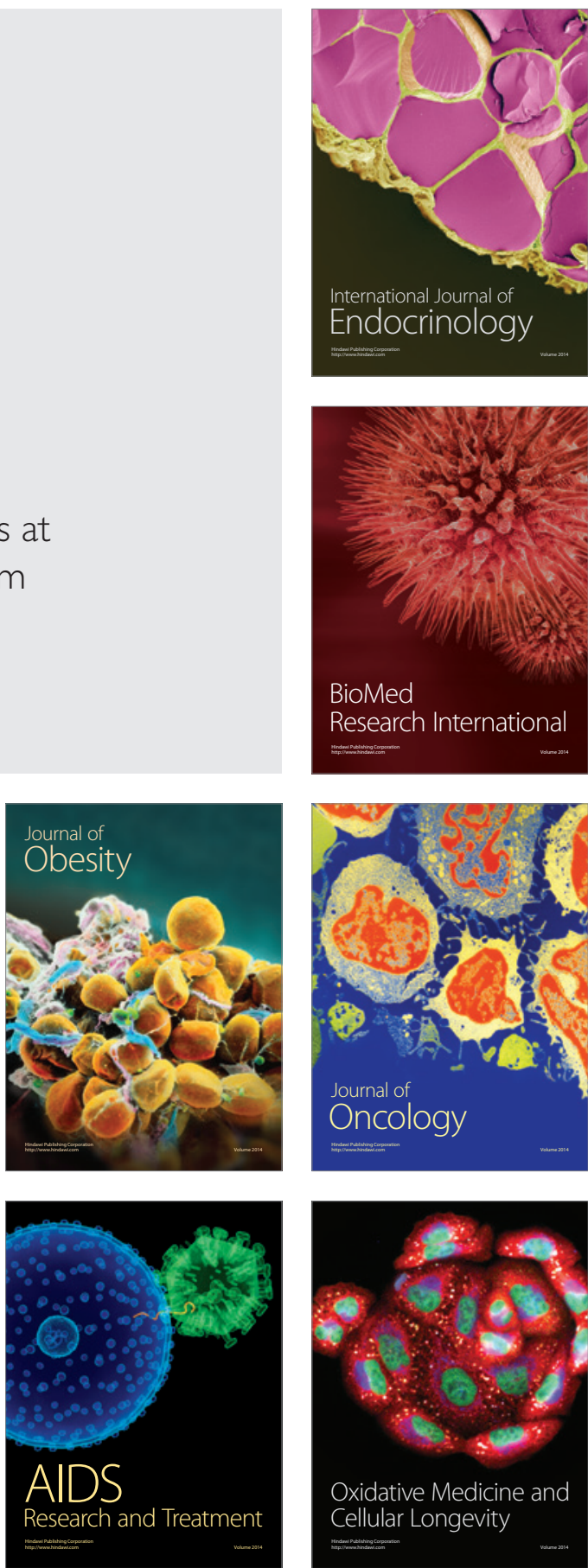